\title{
Synthesis and Properties of Soap Types of Double-Chain Cleavable Surfactants Derived from Pyruvate
}

\author{
Daisuke Ono, Shingo Yamamura, Masaki NaKamura and Tokuji TakedA* \\ Osaka Municipal Technical Research Institute \\ (1-6-50, Morinomiya, Joto-ku, Osaka 536-8553, JAPAN)
}

Edited by K. Nakamura, Kyoto Univ., and accepted September 15, 2003 (received for review July 30, 2003)

\begin{abstract}
Novel double-chain cleavable surfactants bearing an acetal group were easily prepared by acid-catalyzed condensation of pyruvate with fatty alcohols (octyl, decyl, dodecyl) followed by alkaline hydrolysis without any expensive reagents and special equipments. These surfactants showed easier micelle formation and greater ability to lower surface tension compared to those of sodium dodecanoate and the previously reported single-chain cleavable surfactant. These double-chain compounds showed good foaming properties at $0.02 \mathrm{wt} \%$. The wetting times of $0.02 \mathrm{wt} \%$ the compounds were almost the same as those of $1 \mathrm{wt} \%$ sodium dodecanoate. They decomposed completely after $40 \mathrm{~min}$ at $\mathrm{pH} 1$. Their biodegradabilities were higher or almost the same as that of sodium dodecanoate.
\end{abstract}

Key words: cleavable surfactant, acetal type, sodium carboxylate type, double-chain surfactant, biodegradation

\section{Introduction}

At present, surfactants are used in many fields such as detergents, paints, toiletries, pharmaceuticals, and now surfactants with excellent surface-active properties or additional functions are highly desired. Therefore, cleavable surfactants have become a focus of great interest in the field of surfactant chemistry. Such compounds are designed so as to decompose into nonsurface-active species or other surfactants with different properties from original surfactants after fulfilling their original functions (1-10).

We have prepared various types of chemocleavable surfactants (11-23) bearing an acetal group, a 1,3-dioxolane ring or an ester group and evaluated their properties. Their surface-active properties including solubility in water and detergency toward cotton cloth were higher than the conventional soap. Biodegradability of these surfactants was higher or almost the same as that of the conventional soap.
Here we report that novel types of surfactants bearing two alkyl groups were synthesized by acid-catalyzed condensation of fatty alcohols with methyl pyruvate followed by alkaline hydrolysis without any expensive reagents and special equipments (Scheme 1). These surfactants could be easily decomposed by acid. Surface-active properties and acid-decomposition profiles of these surfactants were examined and compared with those of the previously reported single-chain cleavable surfactant 3 (Fig. 1) bearing a 1,3-dioxolane ring derived from pyruvate (17). Biodegradabilities of the surfactants were evaluated: surfactants with high biodegradative properties have been desired from an ecological standpoint.

\section{Experimental}

\subsection{Materials and Synthesis of Acetal Derivatives}

All the starting materials are commercially products

\footnotetext{
*Correspondence to: Tokuji TAKEDA, Osaka Municipal Technical Research Institute, 1-6-50, Morinomiya, Joto-ku, Osaka 536-8553, JAPAN

E-mail: tktakeda@omtri.city.osaka.jp
} 


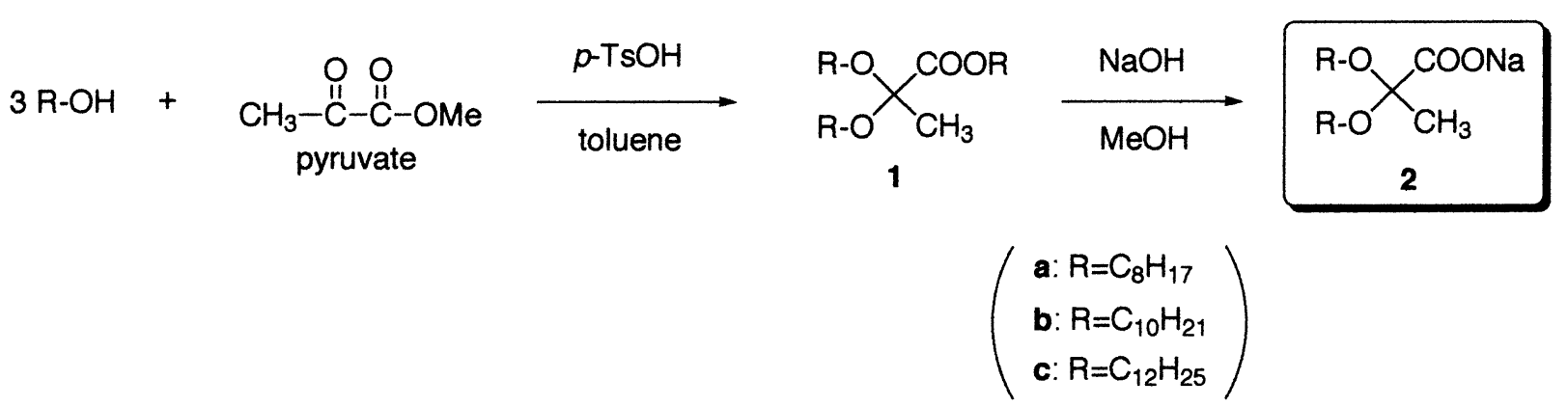

Scheme 1 Synthesis of Carboxylate Types of Acid-Sensitive Cleavable Surfactants.
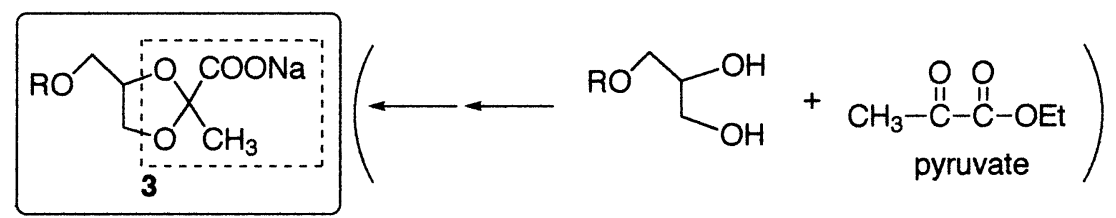

(3b: $\mathrm{R}=\mathrm{C}_{10} \mathrm{H}_{21}, 3 \mathbf{c}: \mathrm{R}=\mathrm{C}_{12} \mathrm{H}_{25}$ )

Fig. 1 The Previously Reported Single-Chain Cleavable Surfactant 3 Bearing a 1,3-Dioxolane Ring Derived from Pyruvate.

(Tokyo Kasei Kogyo Co.). The target double-chain cleavable surfactants were synthesized by the acid-catalyzed condensation of fatty alcohols with methyl pyruvate.

Infrared spectra were recorded on a Shimadzu FT-IR DR-8100. ${ }^{1} \mathrm{H}-\mathrm{NMR}$ spectra were measured in $\mathrm{CDCl}_{3}$ or $\mathrm{CD}_{3} \mathrm{OD}$ with a JEOL JNM-EX270 (270 MHz) spectrometer using TMS as an internal standard.

$2 \cdot 1 \cdot 1$ Double-chain acetal compound (1a), as a typical procedure

In a round-bottomed flask fitted with a stirrer and Dean-Stark receiver, octyl alcohol $(5.21 \mathrm{~g}, 40 \mathrm{mmol})$, methyl pyruvate $(1.02 \mathrm{~g}, 10 \mathrm{mmol})$ and $p$-toluenesulfonic acid ( $p$-TsOH) $(0.10 \mathrm{~g}, 0.5 \mathrm{mmol})$ were dissolved in toluene $(40 \mathrm{~mL})$. The solution was refluxed for $4 \mathrm{~h}$. The toluene solution was washed twice with $5 \%$ $\mathrm{NaHCO}_{3}$ aqueous solution $(30 \mathrm{~mL})$ and saturated $\mathrm{NaCl}$ $(30 \mathrm{~mL})$. The organic layer was dried with $\mathrm{MgSO}_{4}$, and the solvent was evaporated. The non-reacted octyl alcohol was removed by Kugelrohr distillation of the residue, and the oily product (1a) was obtained. yield: $3.49 \mathrm{~g}(79 \%)$

$2 \cdot 1 \cdot 2$ Sodium carboxylate double-chain surfactant (2a), as a typical procedure

In a round-bottomed flask fitted with a stirrer, 1a
(4.42 g, $10 \mathrm{mmol})$ and $\mathrm{NaOH}(0.40 \mathrm{~g}, 10 \mathrm{mmol})$ were dissolved in the mixture of methanol $(20 \mathrm{~mL})$ and hexane $(10 \mathrm{~mL})$. The solution was stirred at $60^{\circ} \mathrm{C}$ for 30 min. The solvent was evaporated, and the waxy product (2a) was isolated by silica gel column chromatography with the following elution system: acetone subsequent to ethanol. yield: $3.10 \mathrm{~g}(88 \%)$.

Chemical yields and analytical data of the products $(\mathbf{1 , 2})$ are summarized in Table $\mathbf{1 .}$

\subsection{Physical Properties}

Krafft point $\left(T_{\mathrm{Kp}}\right)$ of the surfactants was determined by the naked eye using a $1 \mathrm{wt} \%$ aqueous solution. The surface tension of a surfactant solution was measured with a Wilhelmy tensiometer (surface tensiometer CBVP-A3; Kyowa Kaimenkagaku Co., Ltd.; platinum plate) at $25^{\circ} \mathrm{C}$. Foaming properties were evaluated by the semi-micro TK method with a $0.02 \mathrm{wt} \%$ aqueous solution at $25^{\circ} \mathrm{C}(24)$. Wetting ability was estimated by the sedimentation time of a piece of felt (JIS-R28W, $15 \times 15 \mathrm{~mm}$ ) from the surface to the bottom of $50 \mathrm{~mL}$ of $0.02 \mathrm{wt} \%$ aqueous surfactant solution in a $100-\mathrm{mL}$ glass cylinder (i.d. $30 \mathrm{~mm}$ ). All surface-active properties were measured in sodium hydroxide solutions at $\mathrm{pH}$ 11. Decomposition properties of the surfactants 
were evaluated by being stirred in aqueous hydrochloric acid. In this procedure, $0.02 \mathrm{M}$ of surfactant, $30 \mathrm{mg}$ of dodecane or tetradecane as an internal standard for GLC and hydrochloric acid were placed in the mixture of water $(20 \mathrm{~mL})$ and hexane $(10 \mathrm{~mL})$ in a $50-\mathrm{mL}$ Erlenmeyer flask equipped with a stopper and stirred. The reaction mixture was monitored by GLC analysis (Shimadzu, GC-14B; column: CBP1-W12-500; 2a: $120^{\circ} \mathrm{C}, \mathbf{2 b}: 140^{\circ} \mathrm{C}, \mathbf{2 c}: 160^{\circ} \mathrm{C}$ ) of the fatty alcohol generated in hexane (13). Biodegradability of the surfactants was evaluated by an oxygen consumption method. The procedure was done according to the guidelines of the Order prescribing the items of test, relating to new chemical substances of the Chemical Substance Control Law (Japanese Law No. 117, 1973) (21). Biochemical oxygen demand (BOD) after 2 wk was determined by the quantity of oxygen consumed. The biodegradability was estimated by:

Biodegradability $(\%)=\mathrm{BOD} / \mathrm{TOD} \times 100$

where TOD refers to the theoretical oxygen demand. The quantity of oxygen consumption was measured with a Coulometer OM-3100 (Ohkura Electronic Co.), which is a BOD meter for closed systems.

\section{Results and Discussion}

The sodium carboxylates (2a-2c) were synthesized from methyl pyruvate by the following two steps: Acidcatalyzed condensation of methyl pyruvate with fatty alcohols in the presence of $p-\mathrm{TsOH}$ in toluene afforded 1, which was purified by Kugelrohr distillation. Alkaline hydrolysis of the resulting ester (1a-1c) by an equivalent of sodium hydroxide in the mixture of methanol and hexane (2:1) afforded $\mathbf{2 a - 2 \mathbf { c }}$ in good yields. Sodium carboxylates (2) were purified by silica gel column chromatography using acetone and then ethanol as an eluent.

Plots of surface tension vs. concentration for compounds $\mathbf{2}$ are shown in Fig. 2. The Krafft point $\left(T_{\mathrm{Kp}}\right)$, the critical micelle concentration $(\mathrm{cmc})$ and the ability to lower surface tension $\left(\gamma_{\mathrm{cmc}}\right)$ of these surfactants are summarized in Table 2, along with reference data for the previously reported single-chain cleavable surfactant 3 and the conventional soap measured under the

Table 1 Preparation and Properties of Double-Chain Acetal Compounds $(\mathbf{1}, \mathbf{2})^{\mathrm{a})}$.

\begin{tabular}{|c|c|c|c|}
\hline Compound & $\begin{array}{l}\text { Yield } \\
(\%)\end{array}$ & $\begin{array}{l}{ }^{1} \mathrm{H}-\mathrm{NMR}^{\mathrm{b})} \\
(\delta)\end{array}$ & $\begin{array}{l}\text { Anal } \\
\text { Found (Calc'd) }\end{array}$ \\
\hline $1 \mathrm{a}$ & $79^{\mathrm{d})}$ & $\begin{array}{l}0.88(\mathrm{t}, 9 \mathrm{H}, \mathrm{J}=6.6), 1.20-1.40(\mathrm{~m}, 30 \mathrm{H}) \\
1.50-1.75(\mathrm{~m}, 9 \mathrm{H}), 3.30-3.50(\mathrm{~m}, 4 \mathrm{H}) \\
4.20(\mathrm{t}, 2 \mathrm{H}, \mathrm{J}=6.8)\end{array}$ & $\begin{array}{l}\text { C, } 72.99(73.25) \\
H, 12.23(12.29)\end{array}$ \\
\hline $1 b$ & $83^{\mathrm{d})}$ & $\begin{array}{l}0.88(\mathrm{t}, 9 \mathrm{H}, \mathrm{J}=6.8), 1.20-1.40(\mathrm{~m}, 42 \mathrm{H}) \\
1.50-1.75(\mathrm{~m}, 9 \mathrm{H}), 3.30-3.55(\mathrm{~m}, 4 \mathrm{H}) \\
4.20(\mathrm{t}, 2 \mathrm{H}, \mathrm{J}=6.8)\end{array}$ & $\begin{array}{l}\text { C, } 74.99(75.23) \\
H, 12.90(12.63)\end{array}$ \\
\hline 1c & $80^{\mathrm{d})}$ & $\begin{array}{l}0.88(\mathrm{t}, 9 \mathrm{H}, \mathrm{J}=6.8), 1.20-1.40(\mathrm{~m}, 54 \mathrm{H}) \\
1.50-1.75(\mathrm{~m}, 9 \mathrm{H}), 3.30-3.55(\mathrm{~m}, 4 \mathrm{H}) \\
4.20(\mathrm{t}, 2 \mathrm{H}, \mathrm{J}=6.6)\end{array}$ & $\begin{array}{l}\text { C, } 76.36(76.66) \\
H, 12.85(12.87)\end{array}$ \\
\hline $2 \mathbf{a}$ & $88^{\mathrm{e})}$ & $\begin{array}{l}0.88(\mathrm{t}, 6 \mathrm{H}, \mathrm{J}=6.8), 1.20-1.45(\mathrm{~m}, 27 \mathrm{H}) \\
1.50-1.70(\mathrm{~m}, 4 \mathrm{H}), 3.40-3.55(\mathrm{~m}, 4 \mathrm{H})\end{array}$ & $\begin{array}{l}\text { C, } 61.60(61.59)^{\mathrm{c})} \\
H, 10.63(10.61)^{\mathrm{c})}\end{array}$ \\
\hline $2 b$ & $85^{\mathrm{e})}$ & $\begin{array}{l}0.88(\mathrm{t}, 6 \mathrm{H}, \mathrm{J}=6.6), 1.20-1.45(\mathrm{~m}, 35 \mathrm{H}) \\
1.50-1.75(\mathrm{~m}, 4 \mathrm{H}), 3.40-3.55(\mathrm{~m}, 4 \mathrm{H})\end{array}$ & $\begin{array}{l}\left.C, 63.38(63.42)^{c}\right) \\
\left.H, 10.99(11.11)^{c}\right)\end{array}$ \\
\hline $2 \mathrm{c}$ & $81^{\mathrm{e})}$ & $\begin{array}{l}0.88(\mathrm{t}, 6 \mathrm{H}, \mathrm{J}=6.8), 1.20-1.45(\mathrm{~m}, 43 \mathrm{H}) \\
1.50-1.75(\mathrm{~m}, 4 \mathrm{H}), 3.40-3.55(\mathrm{~m}, 4 \mathrm{H})\end{array}$ & $\begin{array}{l}\left.C, 63.94(63.62)^{c}\right) \\
\left.H, 11.84(11.47)^{c}\right)\end{array}$ \\
\hline
\end{tabular}

a) IR spectra (neat): 1a,b,c: $2950,1740,1470$ and $1140 \mathrm{~cm}^{-1}$; 2a,b,c: $2920,1620,1470$ and $1160 \mathrm{~cm}^{-1}$.

b) $\mathrm{In}_{\mathrm{CDCl}_{3}}(\mathbf{1})$ and $\mathrm{CD}_{3} \mathrm{OD}(\mathbf{2})$, TMS as an internal standard.

c) Calculation values of $\mathbf{2}$ are based on the assumption that these compounds contain bound water.

d) Based on methyl pyruvate.

e) Based on $\mathbf{1}$. 
same conditions.

Although 2a-c were insoluble in water at $0.1 \mathrm{wt} \%$ and soluble in water at any temperature at $0.02 \mathrm{wt} \%$, they dispersed uniformly in aqueous alkaline solution at $0.1 \mathrm{wt} \%$ because of the shape of a double-chain type of these surfactants with one head ionic group.

The cmc values of a series of surfactants 2 with two lipophilic chains and one carboxylate group were surprisingly smaller than that of general soap with one longer lipophilic chain and one hydrophilic group such as sodium dodecanoate. Sodium dodecanoate showed about 40 times high $\mathrm{cmc}$ value as $\mathbf{2 a}$, which had the shortest alkyl chains among the compounds in this work. The cmc value of $\mathbf{2} \mathbf{a}$ was smaller than that of $\mathbf{3} \mathbf{b}$ bearing a decyl group. The $\mathbf{c m c}$ of $\mathbf{2} \mathbf{b}$ bearing two decyl groups was about one order of magnitude smaller than that of $\mathbf{3 b}$. One possibility of smaller $\mathrm{cmc}$ of $\mathbf{2}$ is that these surfactants have longer carbon atom chain. The $\gamma_{\mathrm{cmc}}$ values of 2 were below $30 \mathrm{mN} / \mathrm{m}$, and were much smaller than those of sodium dodecanoate and $\mathbf{3}$. They may be caused by closer packing of $\mathbf{2}$ at surface than 3. The carbon-chain length of 2a-c did not affect to the $\gamma_{\mathrm{cmc}}$. It is interesting that 2a showed almost the same cmc value and $\gamma_{\mathrm{cmc}}$ compared to sodium octadecanoate, which have similar total number of carbon atoms. In the range of this work, a series of cleavable surfactants $\mathbf{2}$ have much better micelle formation and
Table 2 Surface-Active Properties of Sodium Carboxylates (2) and Reference Compounds ${ }^{a}$.

\begin{tabular}{|c|c|c|c|c|}
\hline \multicolumn{2}{|c|}{ Compound } & $\begin{array}{l}T_{\mathrm{Kp}}{ }^{\mathrm{b})} \\
\left({ }^{\circ} \mathrm{C}\right)\end{array}$ & $\begin{array}{c}\mathrm{cmc} \\
(\mathrm{mM})\end{array}$ & $\begin{array}{c}\gamma_{\mathrm{cmc}} \\
(\mathrm{mN} / \mathrm{m})\end{array}$ \\
\hline $\mathbf{2 a}$ & $\mathrm{C}_{8} \mathrm{H}_{17}$ & $\left.--{ }^{c}\right)$ & 0.50 & 27.5 \\
\hline $2 \mathbf{b}$ & $\mathrm{C}_{10} \mathrm{H}_{21}$ & $\left.--{ }^{c}\right)$ & 0.080 & 26.0 \\
\hline $2 c$ & $\mathrm{C}_{12} \mathrm{H}_{25}$ & $--{ }^{c}$ & 0.014 & 27.5 \\
\hline \multicolumn{5}{|c|}{ (reference compounds) } \\
\hline $3 \mathbf{b}^{\mathrm{d})}$ & $\mathrm{C}_{10} \mathrm{H}_{21}$ & $<0$ & 1.2 & 32.0 \\
\hline $3 c^{d)}$ & $\mathrm{C}_{12} \mathrm{H}_{25}$ & $<0$ & 0.12 & 31.0 \\
\hline \multicolumn{2}{|c|}{$\mathrm{C}_{11} \mathrm{H}_{21} \mathrm{COONa}$} & 19.0 & 20.0 & 37.5 \\
\hline \multicolumn{2}{|c|}{$\mathrm{C}_{17} \mathrm{H}_{35} \mathrm{COONa}$} & --- & 0.34 & 28.0 \\
\hline
\end{tabular}

a) At $25^{\circ} \mathrm{C}$.

b) At $1 \mathrm{wt} \%$.

c) The compounds 2 were insoluble in water at $0.1 \mathrm{wt} \%$.

d) Cited in reference 17 .

the ability to lower surface tension than the conventional soap and the cleavable surfactant 3 with the same alkyl chain.

The foaming properties and wetting property of 2 and reference compounds are shown in Table 3.

The foaming properties of $\mathbf{2}$ at $0.02 \mathrm{wt} \%$ were similar to those of $\mathbf{3 b}$ at $0.1 \mathrm{wt} \%$ and were better than those of $1 \mathrm{wt} \%$ sodium dodecanoate in spite of lower concentration.

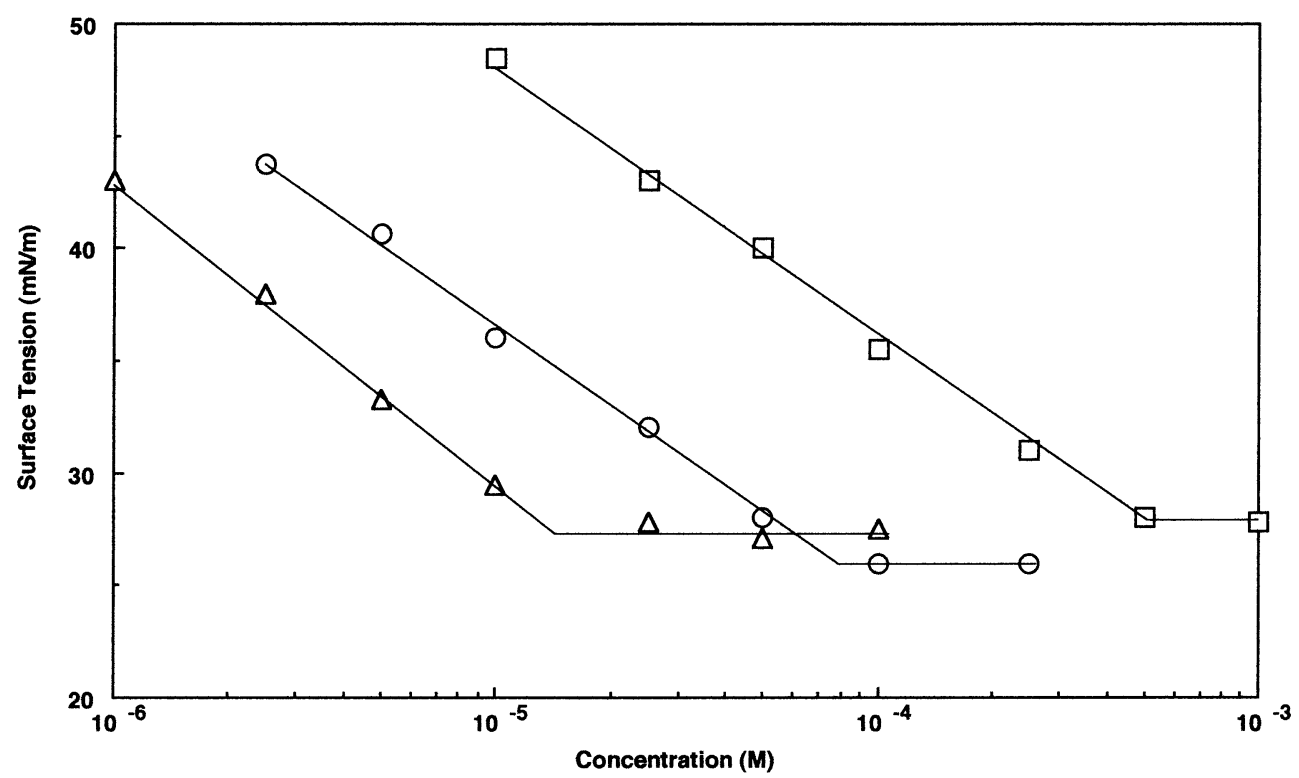

Fig. 2 Surface Tension-Concentration Plots of Aqueous Surfactant Solutions of Compounds $\mathbf{2}$ at $25^{\circ} \mathrm{C}: \square, \mathbf{2 a} ; \bigcirc, \mathbf{2 b} ; \triangle, \mathbf{2 c}$. 
Wetting times of $\mathbf{2}$ at $0.02 \mathrm{wt} \%$ with a felt chip were almost the same as that of sodium dodecanoate at 1 $w t \% ; 2$ showed the better wetting power than sodium dodecanoate. This may be caused by the double-chain structure of 2.

The carbon-chain length of $\mathbf{2 a - c}$ did not affect to the foaming properties and wetting ability. Thus, the double-chain structure in the surfactants is important rather than carbon chain length.

The decomposition properties of $\mathbf{2} \mathbf{a}$ were investigated by reaction with dilute hydrochloric acid. A probable course of the decomposition based on these results is illustrated in Scheme 2.

Degradation of 2a proceeded almost completely after $40 \mathrm{~min}$ at $\mathrm{pH}$ 1. Although degradation of $\mathbf{3}$ was reported to $80 \mathrm{~min}$ at $\mathrm{pH} 1$ (17) and thought to be less sensitive to acid than that of $\mathbf{2}$, the conditions used for measurement are different. The reaction of $\mathbf{2}$ was monitored by GLC and that of $\mathbf{3}$ was checked by NMR. In the case of GLC analysis, the reaction was done in a stirred solution. On the other hand, in the case of ${ }^{1} \mathrm{H}$ NMR analysis (12), the acidic solution was not stirred. The ${ }^{1} \mathrm{H}$ NMR spectrum of compounds 2 in $\mathrm{D}_{2} \mathrm{O}$ contained no discernible signals for $\mathbf{2}$, probably because the lack of signals is consistent with the absence of micelles and with the presence of vesicles or other large aggregates (25). The presence of aggregates with a hydrodynamic diameter of about $125 \mathrm{~nm}(\mathbf{2 a})$ and $240 \mathrm{~nm}(\mathbf{2 b}$ and $\mathbf{2 c})$ was observed by DLS analysis. At $\mathrm{pH} \mathrm{3,} \mathrm{however,} \mathrm{2a}$ was stable in the form of free acid (in the style of the proposed intermediate in Scheme 2), and the hydrolysis of the acetal was not observed for a week. Similar decomposition rates were also observed in the case of $\mathbf{2 b}$ and $\mathbf{2 c}$. It has been confirmed that these compounds 2 are stable at ambient temperature for at least five months.

Finally, the biodegradability of $\mathbf{2}$ was measured by the BOD method in the presence of activated sludge. Biodegradability data for compounds after 2 wk are shown in Fig. 3, along with the data for compound 3, sodium dodecanoate and sodium $n$-dodecylbenzenesulfonate (LAS) measured under the same conditions.

The biodegradability of these cleavable surfactants 2 was almost the same compared with that of sodium dodecanoate, which is known to be a good biodegradable compound. The order of biodegradabilities was: $\mathbf{3}>\mathbf{2 a}>\mathbf{2 b}>\mathbf{2 c}$. It seems that the higher the hydrophilicity becomes, the better the biodegradability of these

Table 3 Foaming Properties and Wetting Times of Sodium Carboxylates

(2) and Reference Compounds ${ }^{\mathrm{a}}$.

\begin{tabular}{|c|c|c|c|c|c|c|c|}
\hline \multicolumn{2}{|c|}{ Compound } & \multicolumn{3}{|c|}{ Foam volume $(\mathrm{mL})^{\mathrm{b})}$} & \multicolumn{3}{|c|}{ Wetting time (s) } \\
\hline & $\mathrm{R}$ & 0 & 1 & $5(\min )$ & 0.02 & 0.5 & $1(\mathrm{wt} \%)$ \\
\hline $\mathbf{2 a}$ & $\mathrm{C}_{8} \mathrm{H}_{17}$ & 250 & 240 & 240 & 8 & --- & --- \\
\hline $2 \mathbf{b}$ & $\mathrm{C}_{10} \mathrm{H}_{21}$ & 250 & 240 & 240 & 5 & --- & --- \\
\hline $2 c$ & $\mathrm{C}_{12} \mathrm{H}_{25}$ & 250 & 250 & 240 & 7 & --- & --- \\
\hline \multicolumn{8}{|c|}{ (reference compounds) } \\
\hline $3 \mathbf{b}^{\mathrm{c})}$ & $\mathrm{C}_{10} \mathrm{H}_{21}$ & $250^{\mathrm{d})}$ & $250^{\mathrm{d})}$ & $200^{\mathrm{d})}$ & --- & --- & --- \\
\hline \multicolumn{2}{|c|}{$\mathrm{C}_{11} \mathrm{H}_{21} \mathrm{COONa}$} & $200^{\mathrm{e})}$ & $200^{\mathrm{e})}$ & $190^{\mathrm{e})}$ & --- & 38 & 5 \\
\hline
\end{tabular}

a) At $25^{\circ} \mathrm{C}$.

b) At $0.02 \mathrm{wt} \%$.

c) Cited in reference 17 .

d) At $0.1 \mathrm{wt} \%$.

e) At $1 \mathrm{wt} \%$. This compound was nonfoaming at $0.1 \mathrm{wt} \%$.

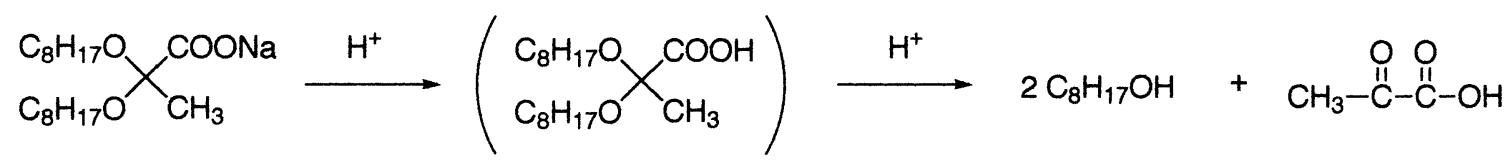

Scheme 2 A Probable Course of the Decomposition of $\mathbf{2 a}$. 


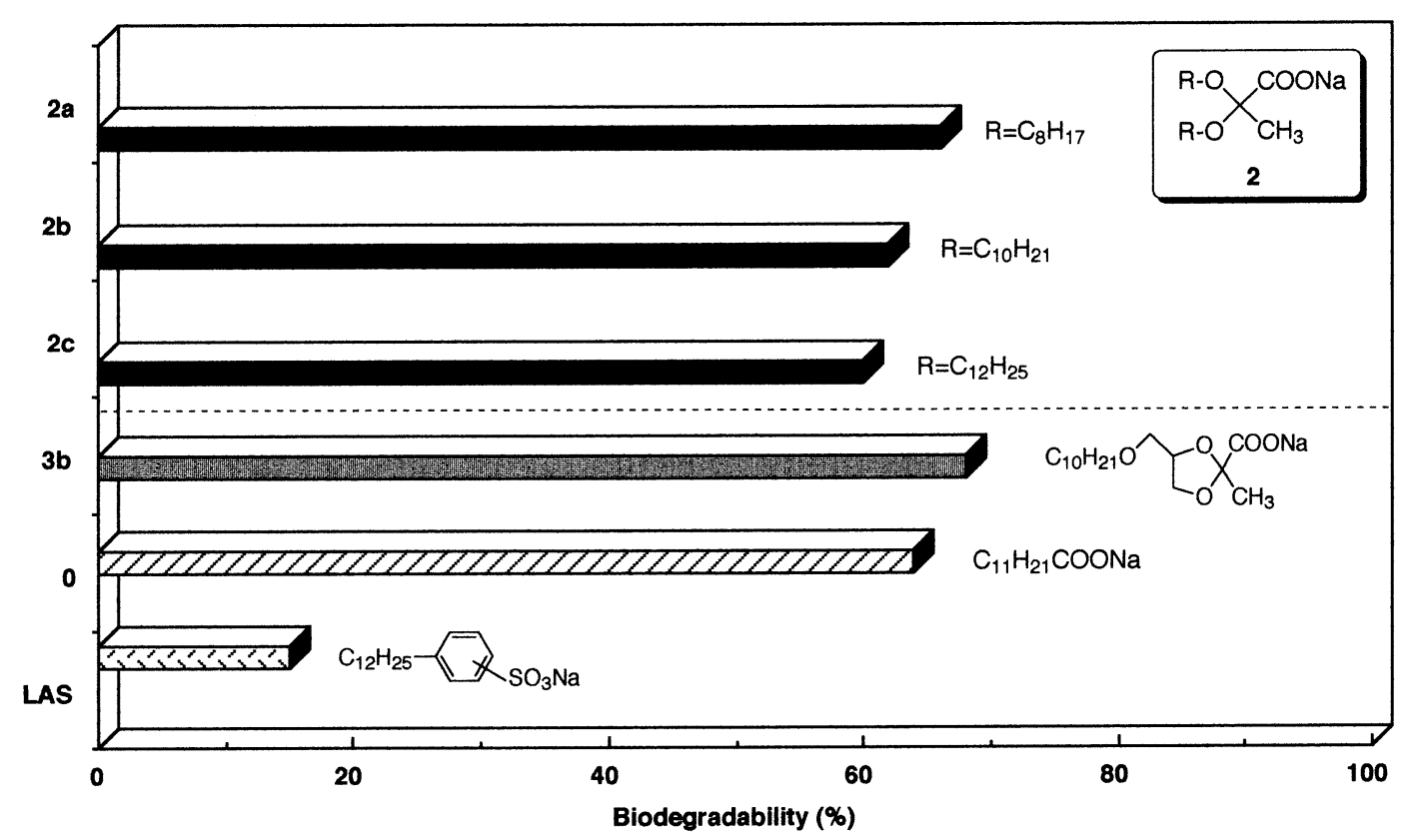

Fig. 3 Biodegradability of Compounds $\mathbf{2 a}, \mathbf{2 b}$ and $\mathbf{2 c}$ after $2 \mathrm{wk}$, along with the Data for Compound 3b, Sodium Dodecanoate and Sodium $n$-Dodecylbenzenesulfonate.

type compounds. These surfactants have much higher biodegradation than LAS, which is popular component in commercial detergents.

\section{References}

1. T. KUWAMURA and H. TAKAHASHI, Structural Effects on the Properties of Nonionic Surfactants. I. The Synthesis and Some Activities of Acetal Type Homogeneous Nonionics, Bull. Chem. Soc. Jpn., Vol. 45, 617-622 (1972).

2. B. BURCZYK and A. SOKOLOWSKI, Relations Between Chemical Structure and Surface Activity I: Synthesis and Properties of Aqueous Solutions of Acetals Formed from Aliphatic Aldehydes and Monoalkyl Ethers of Ethylene Glycols, Tenside Surfactants Deterg., Vol. 15, 68-71 (1978).

3. D.A. JAEGER and M.R. FREG, Preparation and Characterization of Destructible Surfactants, J. Org. Chem., Vol. 47. 311-315 (1982).

4. T. KIDA, A. MASUYAMA and M. OKAHARA, Preparation of Trihydroxy-Carboxylates Bearing a Long-Chain Alkyl Acetal Group from Glucono-1,5-Lactone, Tetrahedron Lett., Vol. 31, 5939-5942 (1990).

5. G.-W. WANG, X.-G. LEI and Y.-C. LIU, Preparation and Properties of Cleavable Dianionic Surfactants with a 1,3-Dioxane Ring, J. Am. Oil Chem. Soc., Vol. 70, 731-732 (1993).

6. T. KIDA, N. MORISHIMA, A. MASUYAMA and Y. NAKATSUJI, New Cleavable Surfactants Derived from Glucono-1,5Lactone, J. Am. Oil Chem. Soc., Vol. 71, 705-710 (1994).
7. G.-W. WANG, Y.-C. LIU, X.-Y. YUAN, X.-G. LEI and Q.-X. GUO, Preparation, Properties, and Applications of VesicleForming Cleavable Surfactants with a 1,3-Dioxane Ring, J. Colloid Interface Sci., Vol. 173, $49-54$ (1995).

8. A. PIASECKI, B. BURCZYK and P. RUCHALA, Synthesis and Surface Properties of Chemodegradable Anionic Surfactants: Sodium Carboxylates of cis-1,3-Dioxane Derivatives, J. Surfactants and Detergents, Vol. 1, 29-35 (1998).

9. D.A. JAEGER, J. WETTSTEIN and A. ZAFER, Cleavable Quaternary Hydrazinium Surfactants, Langmuir, Vol. 14, 1940-1941 (1998).

10. A. PIASECKI and A. MAYHEW, Synthesis and Surface Properties of Chemodegradable Anionic Surfactants: Diastereomeric (2-n-alkyl-1,3-dioxan-5-yl) Sulfates with Monovalent CounterIons, J. Surfactants and Detergents, Vol. 3, 59-65 (2000).

11. S. YAMAMURA, M. NAKAMURA and T. TAKEDA, Synthesis and Properties of Destructible Anionic and Cationic Surfactants with a 1,3-Dioxolane Ring, J. Am. Oil Chem. Soc., Vol. 66, 1165-1170 (1989).

12. D. ONO, A. MASUYAMA and M. OKAHARA, Preparation of New Acetal Type Cleavable Surfactants from Epichlorohydrin, J. Org. Chem., Vol. 55, 4461-4464 (1990).

13. S. YAMAMURA, K. SHIMAKI, T. NAKAJIMA, T. TAKEDA, I. IKEDA and M. OKAHARA, Synthesis and Properties of Destructible Cationic Surfactants with a 1,3-Dioxolane Ring from Acetonyl Alkyl Ether or Aldehyde, Yukagaku, Vol. 40, 1619 (1991).

14. S. YAMAMURA, M. NAKAMURA, K. TANAKA and T. TAKEDA, Synthesis and Properties of Acetal-Containing Sur- 
face Active Alkanolamines and Aminopolyethers, Yukagaku, Vol. 40, 104-108 (1991).

15. S. YAMAMURA, M. NAKAMURA, K. KASAI, H. SATO and T. TAKEDA, Synthesis and Properties of Destructible Anionic Surfactants with a 1,3-Dioxolane Ring and Their Use as Emulsifier for Emulsion Polymerization, Yukagaku, Vol. 40, 1002-1006 (1991).

16. D. ONO, A. MASUYAMA, T. TANAKA and M. OKAHARA, Cleavable Surfactants of the Acetal Type "Properties of New Acetal Types of Cleavable Surfactants Derived from Epichlorhydrin", Tenside Surfactants Deterg., Vol. 29, 412-417 (1992).

17. D. ONO, A. MASUYAMA, Y. NAKATSUJI, M. OKAHARA, S. YAMAMURA and T. TAKEDA, Preparation, Surface-Active Properties and Acid Decomposition Profiles of a New "Soap" Bearing a 1,3-Dioxolane Ring, J. Am. Oil Chem. Soc., Vol. 70, 29-36 (1993).

18. D. ONO, T. TANAKA, A. MASUYAMA, Y. NAKATSUJI and M. OKAHARA, Preparation and Properties of Bis(sodium carboxylate) Types of Cleavable Surfactants Derived from Diethyl Tartrate and Fatty Carbonyl Compounds, Yukagaku, Vol. 42, 10 16 (1993)

19. D. ONO, S. YAMAMURA, M. NAKAMURA, T. TAKEDA, T. TANAKA, A. MASUYAMA and Y. NAKATSUJI, Synthesis and Properties of Soap Types of Cleavable Surfactants Bearing a
1,3-Dioxolane Ring Derived from Long-chain Epoxides and Ethyl Levulinate, Yukagaku, Vol. 42, 965-971 (1993).

20. T. KIDA, K. YURUGI, A. MASUYAMA, Y. NAKATSUJI, D. ONO and T. TAKEDA, Preparation and Properties of New Surfactants Containing D-Glucosamine as the Building Block, $J$. Am. Oil Chem. Soc., Vol. 72, 773-780 (1995).

21. D. ONO, S. YAMAMURA, M. NAKAMURA, T. TAKEDA, A. MASUYAMA and Y. NAKATSUJI, Biodegradation of Different Carboxylate Types of Cleavable Surfactants Bearing a 1,3-Dioxolane Ring, J. Am. Oil Chem. Soc., Vol. 72, 853-856 (1995).

22. A. MASUYAMA, D. ONO, A. YAMAMOTO, T. KIDA, Y. NAKATSUJI and T. TAKEDA, Betaine Types of Surfactants Bearing a 1,3-Dioxolane Ring, Yukagaku, Vol. 44, 446-450 (1995).

23. D. ONO, S. YAMAMURA, M. NAKAMURA and T. TAKEDA, Synthesis and Properties of Bis(sodium sulfonated ester) Types of Cleavable Surfactants Derived from 1-O-Alkylglycerols, $J$. Surfactants and Detergents, Vol. 1, 201-206 (1998).

24. W. YANO and W. KIMURA, Studies on the Evaluation Methods of Surface Active Agents. II. Foam Test: Semimicro Improved TK-Method, Yukagaku, Vol. 11, 138-144 (1962).

25. J.L. BROWNING, in Liposomes: From Physical Structure to Therapeutic Applications (C.G. KNIGHT, ed.), Elsevier, NorthHolland, New York, Chapter 7 (1981). 